\title{
Biodemographic and live cycle development comparison of three genetic populations of Tribolium castaneum Herbst (Coleoptera, Tenebrionidae).
}

\author{
Toffène Diome ${ }^{1.3}$, Cheikh Thiaw ${ }^{2}$, Amy Collé Guèye ${ }^{1.3}$, Assane Ndong ${ }^{1.3}$, Malick Sarr ${ }^{3}$, Mbaye Diop \\ 2, Mbacké Sembène 1.3 \\ 1. Centre de Biologie pour la Gestion des Populations (CBGP); Institut de Recherche pour le développement (IRD) \\ Bel-Air Sénégal \\ 2. "Senegalese Institute of Agricultural Research/National Center of Agronomics Research (ISRA- CNRA); Box: 53 \\ Senegal. \\ 3. Département de Biologie Animale, Faculté des Sciences et Techniques, Université C.A. Diop, B.P. 5005 Dakar, \\ Sénégal \\ Corresponding author: Toffène DIOME, e-mail: eltof@yahoo.fr
}

Original submitted in on $11^{\text {th }}$ September 2014. Published online at www.m.elewa.org on $30^{\text {th }}$ September 2015

http://dx.doi.org/10.4314/jab.v93i1.6

\begin{abstract}
Tribolium castaneum is a cosmopolitan parasite of dry agricultural products. It is harmful and must be the subject of a rational struggle to protect grains during the storage and preservation.

Objective: The objective of this study is to evaluate cycles of development of the populations genetically differentiated.

Methodology and results: Grains of millet were placed in eight Petri dishes and infested by three (3) couples of $T$. castaneum aged between three to ten days for 24 hours. A follow up of the eggs from the laying up to the emergence of the adults was done in order to determine the duration of the different stages. The results showed that the $T$. castaneum cycle of development differ between those nondifferentiated ones. The average life development of the F1 of $T$. castaneum is $28.32 \pm 1.70$ days in Djilas, $32.30 \pm 3.69$ days in Karang and $31.07 \pm 2.23$ days in Diaroume. The average life development of the $F 2$ of T. castaneum in Djilas is $29.30 \pm 2.71$ day's $35.58 \pm 5.24$ days in Karang and $33.36 \pm 4.21$ days in Diaroume. Between populations genetically differentiated (Djilas and Karang on the one hand and between Djilas and Diaroume on the other hand) the gap of the cycle of development is significant. On the other, between Karang and Diaroume, two populations genetically no differentiated, the difference (gap) of the cycle of development is not significant. The sex ratio is in favour of females in the three localities and in the two generations.

Conclusion and application of results: The producers should not mix their own grain to those from markets or other localities to avoid increasing the genetic diversity or introduce short-cycle populations in their storage areas. Indeed, populations of $T$. castaneum from Karang and Diaroume are genetically identical and have the same development cycle. The cycle of the population of $T$. castaneum of Djilas (less than 30 days) is shorter than the other two populations of Karang and Diaroume (over 30 days).
\end{abstract}

Key words: Tribolium castaneum, genetic differentiation, cycle of development. 


\section{Diome et al. J. Appl. Biosci. 2015 Biodemographic and live cycle development comparison of three}

genetic populations of Tribolium castaneum Herbst (Coleoptera, Tenebrionidae).

\section{INTRODUCTION}

Insects can cause devastating losses by reducing the quality and the quantity of stocked products (Bounechada, 2011). In Sénégal, the specimens encountered in the stocks of fonio, maize and millet belong to eight genus following the order of the Coleoptera beetle (Sitophilus, Prostephanus, Tribolium, Rhyzopertha, Cryptolestes, Trogoderma, Oryzaephilus, Carpophilus) dispatched into six families (Curculionidae,Cucujidae,Bostrichidae, dermestidae, Nitidulidae and Tenebrionidae) (Ndao, 2011). Tribolium castaneum is one of the most common devastating tropical beetles of stocked products and main devastator of the cereal (Cotton, 1963 in Prabha Kumari, 2011). Because of its adaptability, $T$. castaneum ranks among the ones to be ostracized all the European countries at all costs (Erwin et al, 1993). Karunakaran et al. (2004) reported that the infestation caused by $T$. castaneum in stock and non-protected wheat reduces almost completely the germination from 9 per cent to 39 per cent after nine months of stocking in Canada and the grains present some damaged nucleus. The grain then emits a foul smelling secretion, which makes the products unsuitable for consumption. The adults and larvae live on the grain and flow. In case of infestation active larvae disappear into the grain and eat there remsted from the light (Mason, 2003). They produce lumpy excrement that is similar to dust. Several parameters may have an effect upon the fertility or about the duration of development for $T$. castaneum. According to Guèye et al. (2012), the

\section{MATERIAL AND METHODS}

Grain of millet as selected samples: To carry out these experiences, grains of millet were taken from the shops of Djilas $\left(14^{\circ} 14^{\prime} \mathrm{N}, 16^{\circ} 38^{\prime} \mathrm{W}\right)$ from Karang $\left(13^{\circ} 35^{\circ} \mathrm{N}, 16^{\circ} 42^{\prime} \mathrm{W}\right)$ and Diaroume (12 $\left.59 \mathrm{~N}, 15^{\circ} 37^{\prime} \mathrm{W}\right)$. The choice of these localities can be explained by their demonstrated genetic differentiation. The grains from these localities were selected from some producers' shops. One part was kept in a freezer for 15 days to sterilize them and the other part was put into jars for a breeding ground.

Tribolium castaneum breeding: Couples were chosen among the first adults emerging from the jars in order obtain second generation which corresponds to cycle of development of $T$. castaneum carry out their larval development in the maize. Different concentrations (1; 0.5 and 0.25$)$ from millet extract have a significant effect in the fertility of $T$. castaneum but do not bring about a difference upon the duration of larval or nymphal development (Ahmed et al., 2009). Temperature acts also upon the duration of the cycle of development of the insect. Indeed, according to Kafka (2009), a temperature of $32^{\circ} \mathrm{C}$ accelerate the duration of the embryonic development (three days) of $T$. castaneum, $25^{\circ} \mathrm{C}$ slows down the embryonic development (seven days) and for a temperature of $23^{\circ} \mathrm{C}$ and $18^{\circ} \mathrm{C}$, the embryos do not develop. According to the same author, at a temperature of $23^{\circ} \mathrm{C}$ and $18^{\circ} \mathrm{C}$, the hatched larvae do not develop too; the adults survive but need higher temperature during a week in order to produce a normal offspring again. The effect of other parameters such as genetic structuring about the cycle of development of $T$. castaneum has not been shown. After a study about the genetic characterization, it demonstrated a significant genetic differentiation between three populations of T. castaneum from Djilas, Karang and Diaroume (Diome et al., 2013). The study raises the question as to whether this genetic differentiation has a physiological base. We are trying to determine the different stages of the cycle of development of these three populations so that to compare them.

$\mathrm{F} 1$ of the experimentation, the laboratory temperature ranged from 25 to $31^{\circ} \mathrm{C}$ and humidity from 41 to $68 \%$. Experimental study of the cycle of development of $T$. castaneum: The experiment was performed on millet. There were eight tins numbered from one to eight for each population and corresponding eight repetitions. Ten grammes of grains was infested by three couples of $T$. castaneum aged between three days to ten days, to ensure that the laying has really started (females of $T$. castaneum start their laying at the age of three days (Camara, 2009). Three couples of T. castaneum (table 1) infested each tin Petri dish. The 
date of infestation, which corresponds, to the first day of the experimentation is recorded.

Statistic analysis: The excel spreadsheet was used to processes the data of the different determined parameters: the duration egg-larvae, egg-pupa, eggadult and the sex-ratio.

Egg-larvae duration: this is the time between the emission of an egg on a seed and the appearance of larvae from it.

Egg-nymph duration: this is the time between the emission of an egg on a seed and the formation of a nymph from it.

Egg-adult duration: this is the time between an egg on a seed and the emergence of the adult from it.

The sex-ratio: it gives the percentage of females compared to all the descendants. If the sex-ratio is

\section{RESULTS}

Average duration of embryonic development of the first F1 and of the second generation (F2) of Tribolium castaneum. : The average duration of embryonic development of the F1 of $T$. castaneum in the store of Djilas is of $4.86 \pm 0.79$ days; $4.54 \pm 0.66$ days in the store of Karang and $5.33 \pm 0.89$ days in the store of Diaroume. The standard deviations were inferior to 1 for the three localities concerned. This shows that the distribution of the data is stable in each of the localities. This average duration (life) for the F2 of $T$. castaneum in the store of Djilas is of $5.20 \pm 0.85$ days; $4.26 \pm 0.68$ days in the store of Karang and $4.46 \pm 0.94$ days in the store of Diaroume. The standards deviation of the data is stable in each of the populations (table 2). The comparison of the average durations of embryonic development of the F1 of $T$. castaneum from the localities of Djilas and Karang reveal a value of $P=0.09>0.05$. The difference between the average duration of the embryonic development of the populations of $T$. castaneum stemming from the localities of Djilas and Karang is not significant at the threshold of risk alpha $=0.05$. Between the $T$. castaneum populations of Diaroume and of Karang, there is a value of $P=0.0000115<0.05$. The difference superior to $50 \%$ then it is in favour of females in the opposite case it takes advantage to males.

The differences of average between the different populations taken by couple were compared by the smallest significant difference about the threshold of $5 \%$ (test Fisher). Fisher starts therefore with the formulation of a hypothesis $\mathrm{HO}$, according to which the statistic (the average for example) of a random sample, draw from a boundless hypothetic population, is equal to a given value (Bourque et al., 2009). Then, we test the difference between the parameter of the distribution of theoretical selection of sample and the statistic observed in the sample. When the compared values differ from more than one gap in advance the hypothesis is rejected (Blais, 1991).

between the duration of embryonic development between the localities of Diaroume and of Karang is significant in $\mathrm{F} 1$ at the threshold of risk alpha $=0.05$. The average duration of embryonic development of the population of $T$. castaneum coming from Djilas and Diaroume in F1 reveals a value of $P=0.048<0.05$, the difference between of the average duration of larvae development of the localities of Djilas and Diaroume is significant in $\mathrm{F} 1$ at the threshold of risk alpha $=0.05$. The comparison between the average duration of embryonic development of the localities of Djilas and Diaroume in F2 reveal a value of $P=0.00039$, the difference is significant between these two populations in $\mathrm{F} 2$ at the threshold of risk alpha $=0.05$. Between the average durations of embryonic development of the populations of $T$. castaneum stemming from the localities of Karang and Diaroume, we have a value of $P=0.000015<0.05$. The difference between the duration of embryonic development of $T$. castaneum stemming from stares of Karang and Diaroume, we have a value of $\mathrm{P}=0.283$. The difference between the duration of embryonic development of the populations of $T$. castaneum of Karang and Diaroume is not significant at the threshold of risk alpha $=0.05$ (table 3). 


\section{Diome et al. J. Appl. Biosci. 2015 Biodemographic and live cycle development comparison of three}

genetic populations of Tribolium castaneum Herbst (Coleoptera, Tenebrionidae).

Table 1: Methodology of infestation of boxes by the species T. castaneum.

\begin{tabular}{llccc}
\hline Species & From & Generation & Number of couples & Number of repetitions \\
\hline \multirow{5}{*}{$T$. castaneum } & Djilas & \multirow{3}{*}{ F1 } & 3 & 8 \\
\cline { 3 - 4 } & Karang & & 3 & 8 \\
\cline { 3 - 4 } & Diaroumé & & 3 & 8 \\
\cline { 2 - 4 } & Djilas & \multirow{3}{*}{ F2 } & 3 & 8 \\
& Karang & & 3 & 8 \\
\cline { 3 - 4 } & Diaroumé & & 3 & 8 \\
\hline
\end{tabular}

Table 2: Average Duration of embryonic development of the F1 and F2 of T. castaneum in the three Communities

\begin{tabular}{lccc}
\hline & Djilas & Karang & Diaroumé \\
\cline { 2 - 3 } & \multicolumn{3}{c}{ F1 } \\
Average Duration (in days) & 4,86 & 4,54 & 5,33 \\
Standard deviation & 0,79 & 0,66 & 0,89 \\
\hline & \multicolumn{3}{c}{4,46} \\
\hline Average Duration (in days) & 5,20 & 4,26 & 0,94 \\
Standard deviation & 0,85 & 0,68 & \\
\hline
\end{tabular}

Average duration egg-nymph of the two generations F1 and F2 of $T$. castaneum; The average duration of eggnymph development of $T$. castaneum in the store of Djilas is $22.58 \pm 1.92$ days, $27.24 \pm 3.41$ days in the store of Karang and $26.49 \pm 2.43$ days in the store of Diaroume. The standard deviations are superior to 1 for the three populations which shows that the distribution of data is unsettled in each of the populations of $T$. castaneum stemming from stores of these localities. The average duration of egg-nymph development of the F2 of $T$. castaneum in the store of Djilas is $24.48 \pm 2.67$ days, $27.48 \pm 3.64$ days in the store of Karang and $28.47 \pm 5.16$ days in the store of Diaroume. The standard deviations are superior to one for the three localities; the data's distribution is then unsettled in each of the store of these localities (table 4) The comparison of the average durations of development of the F1 between the populations of $T$. castaneum stemming from Djilas and Karang from the laying to the appearance of nymphs reveals a probability value $P=5.9010^{-8}<0.05$. The difference between the average durations egg-nymph of $T$. castaneum of Djilas and Karand is significant at the threshold of risk alpha $=0.05$. It has been the same for the average duration of the development of the F1 between the populations of $T$. castaneum stemming from Djilas and Diaroume from the laying to the appearance of nymphs which reveals a probability value $P=3.48 \quad 10^{-6}<0.05$. The difference between the average durations egg-nymph of $T$. castaneum coming from the stores of the localities of
Djilas and Diaroume is significant at the threshold of risk alpha $=0.05$. In return, the comparison of the average durations of development between the populations of the F1 of $T$. castaneum from Karang and Diaroume from the laying to the appearance of nymphs reveals a probability value $P=0.294>0.05$. The difference between the average duration egg-nymph of the stores of the localities of Diaroume and Karang is not significant at the threshold of risk alpha $=0.05$. Between the average durations of development from the laying to the appearance of the nymph of the second generation (F2) of the populations of $T$. castaneum stemming from Djilas and Karang, we have a probability value of $P=0.000971<0.05$. The difference between the average duration egg-nymph of $T$. castaneum from the stores of these localities is significant at the threshold of risk of alpha $=0.05$. The comparison of the average durations of development of the populations of $T$. castaneum stemming from Djilas and Diaroume from the laying to the appearance of nymph reveals a probability value $\mathrm{P}=0.000152<0.05$. The difference between the average durations eggnymph of the populations of $T$. castaneum from the stores of the localities such as Djilas and Diaroume is significant at the threshold of risk alpha $=0.05$. It reveals also a probability value $\mathrm{P}=0.346>0.05$ between the average durations of development of the egg until the appearance of the nymphs of the populations of $T$. castaneum from stores of Karang and Diaroume. The difference between the average durations egg-nymph 


\section{Diome et al. J. Appl. Biosci. 2015 Biodemographic and live cycle development comparison of three genetic populations of Tribolium castaneum Herbst (Coleoptera, Tenebrionidae).}

of $T$. castaneum between the stores of the localities of

of risk alpha $=0.05$ (table 5).

Diaroume and Karang is not significant at the threshold

Table 3: Comparison of average durations of embryonic development of the F1 and F2 of $T$. castaneum

\begin{tabular}{llll}
\hline Shops & Djilas & \multicolumn{1}{l}{ Karang } \\
\hline & & $\mathrm{F} 1$ & \\
\hline $\begin{array}{l}\text { Diaroume } \\
\text { Karang }\end{array}$ & $\mathrm{P}=0.048$ & & $\mathrm{P}=0.000015$ \\
& $\mathrm{P}=0.09$ & & \\
\hline & & $\mathrm{F} 2$ & $\mathrm{P}=0.283$ \\
\hline Diaroume & $\mathrm{P}=0.00039$ & \\
Karang & $\mathrm{P}=0.0000115$ & \\
\hline
\end{tabular}

Table 4: Average durations egg-pupa of the F1 and F2 of T. castaneum

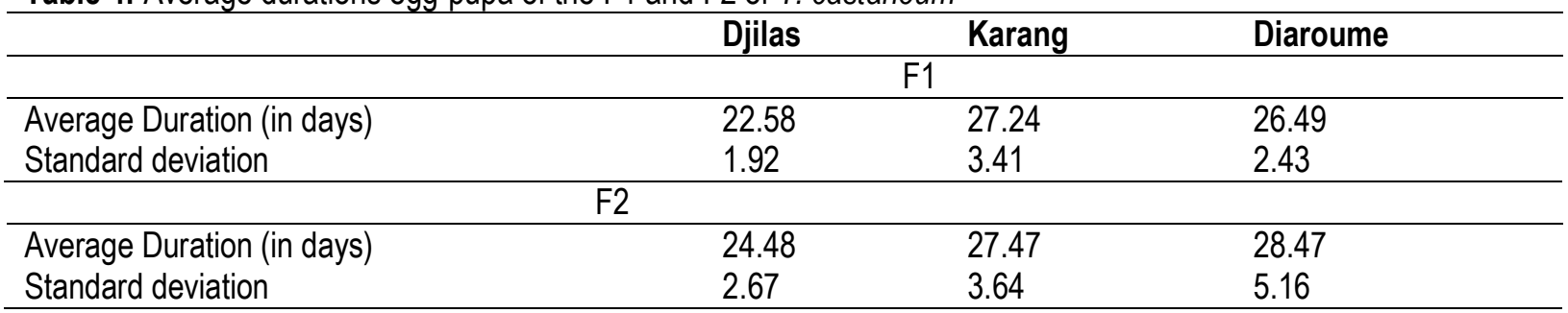

Table 5: Comparison of durations egg-pupa of the F1 and F2 of $T$. castaneum

\begin{tabular}{|c|c|c|}
\hline Shops & Djilas & Karang \\
\hline \multicolumn{3}{|c|}{ F1 } \\
\hline Diaroume & $P=3.48 E-06$ & $P=0,294$ \\
\hline Karang & $P=5.90 \mathrm{E}-08$ & \\
\hline \multicolumn{3}{|c|}{ F2 } \\
\hline Diaroume & $P=0.000152$ & $\mathrm{P}=0.346$ \\
\hline Karang & $\mathrm{P}=0.000971$ & \\
\hline
\end{tabular}

Average durations egg-adult of the F1 and F2 of $T$. castaneum: The average duration of development of $T$. castaneum in the stores of Djilas is $28.32 \pm 1.70$ days, $32.8 \pm 3.69$ days in that of Karang and $31.07 \pm 2.23$ days in the store of Diaroume. The standard deviations are superior to one as for as the three localities are concerned, which shows that the data distribution is unsettled in each store of these three localities. The average duration of development of the F2 of $T$. castaneum in the store of Djilas is $29.30 \pm 2.71$ days, $35.58 \pm 5.24$ days in that of Karang and $33.36 \pm 4.21$ days in the store of Diaroume. The standard deviations are superior to one for these three localities; the data distribution is unsettled in each store in each store of these three localities (table 6). The comparison of the average durations of development of the F1 of $T$. castaneum from Djilas and Karang shows a probability value $P=1.22 \quad 10^{-5}<0.05$, the difference between the cycles of development of $T$. castaneum stemming from the stores of the localities such as Djilas and Karang at the threshold of risk alpha 0.05 . The comparison of the average durations of development of the F1 of the $T$. castaneum populations stemming from Djilas and Diaroume from the laying to the appearance of the adults reveals a probability value $\mathrm{P}=1.42 \quad 10-5<0.05$. The difference between the average durations eggadult of the $T$. castaneum populations stemming from the stores of these two localities is significant at the threshold of risk alpha $=0.05$. It shows also that between the average durations of development from the laying to the appearance of the adult of $T$. castaneum coming from the stores of the localities of Diaroume and 


\section{Diome et al. J. Appl. Biosci. 2015 Biodemographic and live cycle development comparison of three genetic populations of Tribolium castaneum Herbst (Coleoptera, Tenebrionidae).}

Karang is not significant $\mathrm{P}=0.019>0.05$ at the threshold alpha $=0.05$. The comparison of average durations of development of the F2 of $T$. castaneum populations stemming from Djilas and Karang shows a probability value $P=5.49910^{-8}<0.05$. The difference between the cycles of development of $T$. castaneum from the stores of the localities of Dijlas and Karang is significant at the threshold of risk alpha $=0.05$. It shows also for the F2 a probability value $\mathrm{P}=0.00023<0.05$ between the $T$. castaneum populations from Djilas and Diaroume which shows that the difference is significant between these populations at the threshold of risk alpha $=0.05$. The comparison of the average durations of development of the F2 of $T$. castaneum from the laying to the appearance of adults between Diaroume and Karang reveals a probability value $P=0.064>0.05$. The difference between the average duration of egg-adult of the stores of localities of Diaroume and Karang is not significant at the threshold of risk alpha=0.05 (table 7).

Table 6: Average durations egg-adult of the F1 of $T$. castaneum.

\begin{tabular}{lccc}
\hline Shops & Djilas & Karang & Diaroume \\
\hline & F1 & & \\
\hline Average Duration (in days) & 28.32 & 32.8 & 31.07 \\
Standard deviation & 1.70 & 3.69 & 2.23 \\
\hline & F2 & & \\
\hline Average Duration (in days) & 29.30 & 35.58 & 33.36 \\
\hline Standard deviation & 2.71 & 5.24 & 4.21 \\
\hline
\end{tabular}

Table 7: Comparison of durations of egg-adult of the F1 and F2 of $T$. castaneum populations.

\begin{tabular}{llll}
\hline Shops & Djilas & \multicolumn{1}{l}{ Karang } \\
\hline & \multicolumn{1}{c}{$\mathrm{F} 1$} & \\
\hline Diaroume & $\mathrm{P}=1.4229 \mathrm{E}-05$ & $\mathrm{P}=0.019$ \\
Karang & $\mathrm{P}=1.221 \mathrm{E}-05$ & \\
\hline & & $\mathrm{F} 2$ & \\
\hline Diaroume & $\mathrm{P}=0.00023$ & $\mathrm{P}=0.346$ \\
\hline Karang & $\mathrm{P}=5.499 \mathrm{E}-8$ & \\
\hline
\end{tabular}

Differentiation between the three populations of $T$. castaneum of Djilas, Karang and Diaroume: The strongest values of the Fst have been obtained between the populations of $T$. castaneum of Djilas and
Diaroume (0.57143). These values are also significant. On the other hand, between Karang and Diaroume the genetic differentiation is negative and not significant (table 8).

Table 8: Genetic differentiation between the three populations of $T$. castaneum

\begin{tabular}{lll}
\hline & Djilas & Karang \\
\hline Karang & $0.46296^{*}$ & \\
Diaroume & $0.57143^{*}$ & $-0,07280$ \\
\hline
\end{tabular}

The sex ratio of the F1 of $T$. castaneum according to the differentiated populations: The sex ratio of the $\mathrm{F} 1$ is in favour of females in the three populations. The females represent $63.15 \%$ of the emerged adults from the population of $T$. castaneum of Djlas, $64.28 \%$ of the adults of Karang and $56 \%$ of that of the adults of
Diaroume. The number of females emerged is superior to the number of males regarding the three populations of the F2 as well. The females represent $59.27 \%$ of the adults emerged from the population of $T$. castaneum of Djilas, $66.66 \%$ of the adults from that of Karang and $59.42 \%$ of the adult from that of Diaroume. The number 


\section{Diome et al. J. Appl. Biosci. 2015 Biodemographic and live cycle development comparison of three genetic populations of Tribolium castaneum Herbst (Coleoptera, Tenebrionidae).}

of emerged females is superior to the number of males in the three populations (table 9).

The mortality rate regarding the two generations F1 and F2 : It results that the larval mortality of the F1 is more important in the population of $T$. castaneum coming from Diaroume $(28.57 \%)$ it is weak in the population of Karang (8.51\%) and Djilas (9.52\%). On the other hand, regarding the F2, the larval mortality is weak in the population of $T$. castaneum of Diaroume $(5 \%)$ just as in the populations of Djilas $10 \%$ and Karang (12\%). The nymph mortality is non-existent in Djilas and in Diaroume in the two generations. On the other hand, for Karang, we have a death rate of $2.3 \%$ in the $\mathrm{F} 1$ and $12 \%$ in the F2 (table 10).

Table 9: Emergence of adults and sex-ratio $(\mathrm{R})$ of two generations $\mathrm{F} 1$ and $\mathrm{F} 2$ of $T$. castaneum in all three populations.

\begin{tabular}{lllllll}
\hline Populations & Number adult & Male & Female & \% Female & Sex-ratio \\
\hline Djilas & & & F1 & & & \\
Karang & 19 & 7 & & 12 & 63.15 & 0.58 \\
Diaroume & 42 & 14 & 27 & 64.28 & 0.51 \\
\hline & 25 & 11 & & 14 & 56 & 0.78 \\
\hline Djilas & 27 & & F2 & & & \\
Karang & 24 & 10 & & 16 & 59.27 & 0.62 \\
Diaroume & 69 & 28 & 16 & 66.66 & 0.5 \\
\hline
\end{tabular}

Table 10: Percentage of larval mortality and indicating

\begin{tabular}{llllll}
\hline Populations & N. larvae & N. nymphs & M. larvae & N. adults & M. Nymphs \\
\hline \multicolumn{5}{c}{} & \multicolumn{5}{c}{ F1 } & 19 & 0 \\
\hline Djilas & 21 & 19 & $9.52 \%$ & 42 & $2.3 \%$ \\
Karang & 47 & 43 & $8.51 \%$ & 25 & 0 \\
Diaroume & 35 & 25 & $28.57 \%$ & & \\
\hline \multicolumn{7}{r}{} & 27 & F2 & 27 & 0 \\
\hline Djilas & 30 & 28 & $12.5 \%$ & 24 & $12 \%$ \\
Karang & 32 & 69 & $5 \%$ & 69 & 0 \\
Diaroume & 73 & &
\end{tabular}

N.: Number, M.: Mortality

\section{DISCUSSION}

This study has demonstrated that the populations of $T$. castaneum from Djilas, Karang and Diaroume are different genetically. The bio-ecology results have shown that both the first generation $\mathrm{F} 1$ and the second generation F2, have a significant difference for the durations of embryonic development between the populations of $T$. castaneum from Djilas (4.86 days) and Diaroume (5.33 days) are concerned. According to Bonneton (2010), the embryogenesis of $T$. castaneum last three days at $30^{\circ} \mathrm{C}$. This duration is inferior to what this study obtained in the populations from the localities of Djilas and Diaroume. Indeed, the temperature was not steady during the testing, which might accentuate the difference mentioned. However, we can think that the duration of embryonic development can differ significantly between the populations of $T$. castaneum genetically differentiated. Diome et al. (2013) have shown that the genetic differentiation is more accentuated between the populations of $T$. castaneum from Djilas and Diaroume. This differentiation could have then an impact on the duration of embryonic development of the insect. For the average duration egg-nymph, the study had a significant difference between the populations from Djilas and Karang on the one hand and between Djilas and Diaroume on the other hand, for the two generations F1and F2 between Karang and Diaroume the difference is not significant. Indeed the genetic differentiation is not significant 
between the populations of $T$. castaneum of these last two localities. We can therefore think that the more there is a genetic differentiation, the more there is a difference in the duration of the cycle of development. The results obtained with the duration egg-nymph are confirmed by the results obtained on the cycle of development of these different populations. The cycle of development of the $T$. castaneum populations of Djilas is shorter and does not exceed thirty days for each of the two generations (F1 and F2). This shows that we can have several generations in this population during the years if the conditions are comfortable in a crucial period of the year. We can meet five generations in a year (Bennett, 2003). According to the Canadian commission of the grains (CCG), the red Tribolium of the flow is among the insects, which infest the stored foodstuff, one of those, which the populations increase the most rapidly. The duration of the cycle of development has slightly increased within each locality from one generation to another, which could be due to a variation of certain climatic parameters during the testing like the temperature and the humidity relative. The temperature and the relative humidity of the air, the type of food (Guèye et al., 2012) the rate of breakage (Seck et al., 1992) have an impact on the duration of the cycle of development of $T$. castaneum. The development of $T$. castaneum stops in below of $22^{\circ} \mathrm{C}$ but it resists very well to the low of hygrometry's (Camara, 2009). The cycle of development is longer in the population of Diaroume $32.8 \pm 3.69$ days in $F 1$ and $35.58 \pm 5.24$ days in F2. According to ISS Suisse, while all the factors are almost optimal, the duration of a generation can be from 27 to 35 days. The cycle in F2 of the $T$. castaneum population of Diaroume is near at hand to that found by Guèye et al. (2012) on the T. castaneum populations erected upon maize ( $36.3 \pm 1.42$ days). The shortest cycle is noted in Djilas and its duration is close to that found by Guèye et al. (2012) and distant to that

\section{ACKNOWLEDGEMENT}

The World Bank program of "West Africa Agricultural Productivity Program" (WAAPP) National Centers of

\section{REFERENCES}

Ahmed S, Zainab A, Nisar S. and Rana N: 2009. Effect of new formulations of neem products on biology of Tribolium castaneum (herbst) (Tenebrionidae: Coleoptera). Pak. Entomol. 2: 133-137. found by Delobel and Tran (1993) who have found an average duration of development from egg to adult on the millet of 26 days at $28 \%$ for an HR of $70 \%$. This shows that the cycle of development of $T$. castaneum can differ between subservient in a same cereal and that the genetic differentiation would play a very important role. In the three populations, the average duration of the cycle of development does not exceed 36 days as well for the first and for the second generation. Some are comparable at the average duration 35 days obtained by Seck et al. (1992) on the $T$. castaneum populations erected in the grains of millet at $0 \%$ of breakage. This could be explained by the capacity of the insect to be able to attack the intact grains. Indeed, it has been for a long time ranked among the secondary devastators but the Canadian commission of the grain (CCG) has ranked it now among the primary devastators. Between genetically non-differentiated populations (like that of Karang and Diaroume), it was noted that a significant difference in their development duration from the bud until the emergence of adults. The non-differentiated populations are located in two different agro-ecological areas, which show that the populations located in different agro-ecological areas can present a genetically homogeneous population genetically (Diome et al., 2012) and the same cycle of development. However, the differentiated populations would present a different duration of the cycle of development. The study noted that, the number of females is higher comparing to that of males in the 3 localities and in the two generations (percentage of females superior to 50 per cent). It can be concluded that the females prevail and tend to have a paramount role in the infestation of stocked grains in the different stores of the localities; this could accentuate the infestation in the stocking spots. The larval death rate of $T$. castaneum being equal to 8.51 percent in Karang, 9.52 percent in Djilas and 28.57 percent in Diaroume.

Excellence and The "Observatoire Homme-Milieu" OHM Tessékéré funded this work.

Arbogast RT: 1991. Beetle: Coleoptera In Ecology and Management of Food-Industry Pests (Edited by Gorham J.R.). Association of Official Analytical Chemicals, Arlington, Virgima. 131176. 
Bennett SM: 2003. Tribolium confusum (Confused Flour Beetle) and Tribolium castaneum (Rust Red Flour Beetle). 3p.

Bonnetone F: 2010. Quand Tribolium complémente la génétique de la drosophile. Medecine/Sciences 26 : 297-303.

Bounechada M and Arab R : 2011. Effet insecticide des plantes Melia azedarach L. et Peganum harmala L. sur $T$. castaneum Herbst (Coleoptera: Tenebrionidae). Agronomie numéro 1.6p.

Camara A: 2009. Lutte contre Sitophilus orizea $L$. (Coléoptères curculionidae) et Tribolium castaneum Herbst (Coléoptère Ténébrionidae) dans les stocks de riz par la technique d'élevage traditionnelle pratiquée en Basse Guinée et utilisation des huiles essentielles végétales. Thèse d'obtention du titre de Docteur en Science de l'environnement, Université du Québec à Montréal. 173p.

Delobel A. and Tran M: 1993. Les coléoptères des denrées alimentaires entreposées dans les régions chaudes. CTA et ORSTROM 424p.

Diome T, Thiaw C, Ndong A, Sarr M, Kane M. and Sembène M: 2012. Haplotype diversity of Tribolium castaneum H. (Coleotera, Tenebrionidae) pest of stored millet in Senegal. Journal of Cell and Animal Biology 13: 192-199.

Diome T, Thiaw C, Sarr M, Ndong A, Kane M, Cissé N. and Sembène M: 2013. Genetic diversity of Tribolium castaneum (Herbst) population in storage infrastructures and agro ecological zones in Senegal. International Journal of Biosciences 9: 248-258
Erwin J., Thomas B., Roman E. and Roger S: 1993. Insectes ravageurs domestiques. Musée d'histoire naturelle de Fribourg 1-48.

Guèye AC, Diome T, Thiaw C, Ndong A, Guèye AN et Sembène $M$ : 2012. Capacity of biodemographic developpment of Tribolium castaneum Herbst (Coleoptera, Tenebrionidae) and Sitophilus zeamais Motschulsky (Coleoptera, Curculionidae) in stored cereals in Senegal. South Asian Journal of Experimental Biology 3: 108-117.

Karunakaran C, Jayas DS, White NDG (2004). Identification of wheat kernels damaged by the redflour beetle using x-ray images. Biosystems Engineering 3: 267-274.

Mason LJ : 2003. Grain Insect Fact Sheet E-224-W: Red and Confused Flour Beetles, Tribolium castaneum (Bhst.) and Tribolium confusum Duval. Purdue University, Department of Entomology.

Ndao A: 2011. Diversité, abondance et prévalence des principaux coléoptéres ravageurs de stocks de fonio, de maïs et de mil au Sénégal. Mémoire de diplôme de Master II en Biologie Animale, Spécialité: Entomologie, UCAD/FST. 30 p.

Prabha Kumari C, Sivadasan R. and Jose A: 2011. Microflora associated with the red flour beetle, Tribolium castaneum (Coleoptera: Tenebrionidae). Journal of Agricultural Technology 6: 1625-1631.

Seck D, Sidibé B. and Fall A: 1992. Observation sur le développement de Tribolium castaneum Herbst sur le mil (Pennisetum typhoïde L.), en fonction du taux de brisure dans le substrat. Soc. r. belge Ent. 35 : 471-475. 